IOS Press

\title{
Phenotypic diversity in antioxidant phytochemical composition among fruits from several genotypes of red raspberry (Rubus idaeus L.)
}

\author{
Tatiana Pirogovskaia ${ }^{\mathrm{a}, \mathrm{c}}$, Chaim Kempler ${ }^{\mathrm{b}}$, David D. Kitts ${ }^{\mathrm{c}}$ and Steven T. Lund ${ }^{\mathrm{a}, \mathrm{c}, *}$ \\ ${ }^{a}$ Faculty of Land and Food Systems, Wine Research Centre, University of British Columbia, \\ Vancouver, BC, Canada \\ ${ }^{\mathrm{b}}$ Pacific Agri-food Research Centre, Agriculture and Agri-Food Canada, Agassiz, BC, Canada \\ ${ }^{\mathrm{c}}$ Food, Nutrition, and Health Program, Faculty of Land and Food Systems, University of British Columbia, \\ Vancouver, BC, Canada
}

Received 5 January 2012; accepted 21 May 2012

\begin{abstract}
The Pacific Northwest in North America, Russia, and Eastern Europe are three major regions of commercial raspberry production worldwide. In British Columbia, Canada, most raspberries are produced for machine harvesting and processing, while some are selected for the fresh market. Due to increasing public awareness of the benefits of consuming antioxidants for improving human health, breeding of functional foods based on phytochemical composition pyramided with other economically important traits in raspberry is desirable. In this study, genotypes of raspberry destined for the fresh market or processing were each investigated for ascorbic acid and anthocyanin compositions. Variations in these compositional traits were assessed along three consecutive years as well as among three sites in the Fraser Valley of British Columbia. There was a wide range of ascorbic acid contents among fruits from different genotypes with a trend among sample years that appeared to be dependent on seasonal temperatures. For two cultivars, eight different anthocyanins were identified, where the rest of the cultivars contained from four to six. Growing conditions influenced anthocyanin levels, while the profiles stayed consistent. Results from this study can aid in selections by geneticists for crosses to improve antioxidant traits through breeding of new raspberry genotypes.
\end{abstract}

Keywords: Ascorbic acid, anthocyanins, antioxidants, LC-MS, soft fruit

\section{Introduction}

Nutritional qualities of fruits have become increasingly relevant for a healthy human diet. The antioxidant action of anthocyanins has been previously reported in the prevention of cancer proliferation in human cell lines [1], lowering of blood pressure in hypertensive stroke-prone rats [2], and the activation of endothelial nitric oxide synthase which induces endothelial-dependent relaxation [3]. Reduction of estrogen-induced mammary tumors in rats treated with ascorbic acid [4] and the promotion of bone health in older humans [5] are some examples of the potential benefits of increasing ascorbic acid in animal diets. Ascorbic acid is widely recognized as an oxygen radical scavenger and an essential nutrient for humans because eight different enzymes use ascorbic acid as electron donor [6]. These

${ }^{*}$ Corresponding author: Steven T. Lund, Wine Research Centre, 241 - 2205 East Mall, University of British Columbia, Vancouver, BC V6T 1Z4 Canada. Tel.: +1 604822 5708; E-mail: stlund@mail.ubc.ca. 
enzymes function in collagen formation [7], carnitine synthesis [8], norepinephrine biosynthesis [9] peptide hormone stabilization [10], and tyrosine metabolism modulation [11].

Molecular breeding approaches are now viable for enhancing the contents of specific healthy phytochemicals in fruits. Genetic background can play an essential role in determining the nutritional qualities of fruits. Until recently, reports of introgressions of nutritional phytochemical traits to breeding programs in fruit species have been limited [6]. Scalzo et al. [12] analyzed a number of phytochemical parameters in selected strawberry genotypes and found significant differences among genotypes for total antioxidant capacity; however, a poor correlation between antioxidant capacity and horticultural attributes such as yield and fruit size was also determined. When crosses were made between clones with desirable horticultural attributes and those with high antioxidant capacity, the authors [12] were able to select progeny that had both desirable commercial attributes and high antioxidant capacity. These results, albeit focused on strawberry, indicate that breeding of functional fruits with improved nutritional properties is feasible and can be coupled with selections for traditional agronomic traits of economic importance.

Raspberry (Rubus idaeus L.) bears red-pigmented, soft fruits containing several antioxidant compounds, including ascorbic acid (vitamin C) and anthocyanin flavonoids. Beekwilder et al. [13] determined that ascorbic acid accounted for $20 \%$ of the total antioxidant capacity in raspberry fruits. We considered that genetic potential may exist among Rubus spp. germplasm to further improve such healthy traits as ascorbic acid content in commercial genotypes through conventional breeding. The extent to which antioxidant capacity or nutritional phytochemical composition differ among raspberry genotypes by season or production site has not been previously reported from a single study. Tosun et al. [14] reported significant differences in antioxidant capacities as well as ascorbate and total phenolic contents among fruits from 11 raspberry genotypes. Our objective here was to extend the findings of Tosun et al. [14] by evaluating genotypic diversity in ascorbic acid and anthocyanin contents from 12 raspberry genotypes and determining whether significant differences for these traits among genotypes may be confounded by variability attributed to harvest season or site.

\section{Materials and methods}

\subsection{Plant material}

Fruits from the floricane raspberry (R.idaeus) cvs., Algonquin, Chilcotin, Cascade Delight, Chilliwack, Cowichan, Haida, Malahat, Meeker, Nootka, Sumner, Tulameen, Washington, Willamette, and two experimental genotypes, 36 and 62, were each harvested in each of three years at commercial maturity (22 July 2008, 17 July 2009, 14 July 2010). Collections were made from one experimental (PARC) and two commercial production sites (HK and AK) located in the Fraser Valley of British Columbia. Year-to-year variability analyses were done using samples from the Pacific Agri-Food Research Centre (PARC) substation in Abbotsford, BC. Site-to-site analyses were performed on the samples from PARC and two commercial production sites, South Alder Farms and Krause Berry Farms, owned by Harvey Kraus (HK) and Alfred Kraus (AK), respectively. Harvest date was determined using the following commercial maturity parameters: 9.3 to $13.0^{\circ}$ Brix, titratable acidity of 1.7 to $2.5 \%$, $\mathrm{pH}$ of 2.6 to 3.9 , and total soluble solids of 15 to $18 \%$. Although agricultural practices were quite similar among three sites, the main soil differences were in the thickness of the veneer. PARC is characterized by orthic humo-ferric podzol soil, HK is $70 \%$ orthic humo-ferric podzol and 30\% luvisolic humo-ferric podzol, while AK is $70 \%$ rego humic gleysol and $30 \%$ gleyed ortstein humo-ferric podzol. Samples were collected in plastic containers or sealed bags and kept on wet ice until they were snap-frozen with liquid nitrogen and stored at $-80^{\circ} \mathrm{C}$ within five hours from harvest. Compositional chemistry analyses were performed on extracts from frozen samples; moisture content comparisons revealed no significant difference among years (data not shown). Mean temperature data for three years was retrieved from a government website, Weather Office, for the Abbotsford area [15]. Trendlines and their linear equations for each year were created using MS Excel software.

\subsection{Determination of ascorbic acid content}

The extraction procedure was modified from Frenich et al. [16] as follows. Two $g$ of fruit drupelets were placed in a solution containing $5 \mathrm{~mL}$ methanol (Sigma-Aldrich Co., Oakville, Ontario, Canada), $25 \mathrm{~mL} 3 \%$ meta-phosphoric 
acid (Sigma-Aldrich), and $8 \%$ acetic acid (Sigma-Aldrich). Each sample was homogenized using a Polytron mixer for one min and then centrifuged at $4{ }^{\circ} \mathrm{C}$ for 30 minutes at $3600 \mathrm{~g}_{\mathrm{n}} .10 \mathrm{~mL}$ of the supernatant were then mixed with $15 \mathrm{~mL}$ of $0.1 \%$ acetic acid solution. An aliquot of the final mixture was transferred to a $1.5 \mathrm{~mL}$ screw-cap amber vial (Agilent Technologies Inc., Mississauga, Ontario, Canada).

An LC/MSD-Trap XCT Plus system equipped with electrospray ionization (ESI) was used to quantify L-ascorbate in each sample. Linear gradient separation was performed on a Zorbax SB-C18 rapid resolution HT $4.5 \times 50 \mathrm{~mm}$, $1.8 \mu \mathrm{m}$ column (Agilent) starting with $2 \%$ solvent B (acetonitrile with $0.2 \%$ formic acid) in $98 \%$ solvent A (water with $0.2 \%$ formic acid) to reach $90 \%$ (acetonitrile with $0.2 \%$ formic acid) at 2.33 minutes along each 5 minute run. Flow rate was $1.0 \mathrm{~mL} \cdot \mathrm{min}$ and $2 \mu \mathrm{L}$ of the sample were injected in triplicate. Quantification was performed by constructing a standard curve with commercially available ascorbic acid (Sigma-Aldrich) and hippuric acid (Sigma-Aldrich) as internal standards. During optimization of MS parameters, it was determined that for ascorbic acid, ESI negative mode showed the best response, whereas for ascorbic and hippuric acids, unprotonated molecular ions $[\mathrm{M}-\mathrm{H}]-\mathrm{m} / z$ 175 and 178, respectively, were monitored (data not shown).

\subsection{Determination of anthocyanin content}

Anthocyanins were extracted according to the method of Mullen et al. [17] with minor modifications. Two g of each fruit sample were extracted with a $30 \mathrm{~mL}$ solution containing $0.1 \% \mathrm{HCl}$ in methanol using a Polytron homogenizer for one minute, followed by vortexing. The extract was centrifuged for $20 \mathrm{~min}$ at $3600 \mathrm{~g}$. One mL supernatant was transferred to a screw cap amber vial and $1 \mu \mathrm{L}$ was then injected into the LC-MS in triplicate.

An LC/MSD-Trap XCT Plus system equipped with electrospray ionization (ESI) was used to quantify anthocyanin composition in each sample. A linear gradient separation was performed on a Zorbax SB-C18 rapid resolution HT $4.5 \times 50 \mathrm{~mm}, 1.8 \mu \mathrm{m}$ column (Agilent) starting with $2 \%$ solvent A (acetonitrile with $2 \%$ (v/v) formic acid) in $98 \%$ solvent B (water with $2 \%$ (v/v) formic acid) and reaching $90 \%$ (acetonitrile with $2 \%$ (v/v) formic acid) (Sigma-Aldrich). Two $\mu \mathrm{L}$ of each sample were injected in triplicate and the flow rate was set at $1.0 \mathrm{~mL}$.min. During optimization of MS parameters, it was determined that for anthocyanins, an ESI positive mode gave the best response (data not shown).

Table 1

Ascorbic acid contents (mg per $100 \mathrm{~g}$ fresh fruit) among three years for 12 genotypes. Overall mean and standard error of the mean (SEM) for two technical replicates are shown. $P$-values for 2-way ANOVAs for genotype, year, and genotype $\times$ year interaction are presented below

\begin{tabular}{|c|c|c|c|c|c|c|c|}
\hline \multirow[t]{2}{*}{ Genotype } & \multicolumn{2}{|c|}{2008} & \multicolumn{2}{|c|}{2009} & \multicolumn{2}{|c|}{2010} & \multirow{2}{*}{$\begin{array}{c}\text { Overall } \\
\text { genotype } \\
\text { mean }\end{array}$} \\
\hline & Mean & SEM & Mean & $\overline{\mathrm{SEM}}$ & Mean & $\overline{\text { SEM }}$ & \\
\hline Genotype 62 & 24.5 & 0.46 & 16.04 & 0.8 & 33.61 & 0.77 & 24.72 \\
\hline Algonquin & 10.29 & 0.26 & 16.54 & 0.84 & 27.27 & 0.1 & 18.03 \\
\hline Chilcotin & 13.55 & 0.41 & 27.22 & 0.14 & 29.7 & 3.59 & 23.49 \\
\hline Chilliwack & 13.65 & 0.14 & 24.67 & 3.02 & 25.59 & 0.24 & 21.30 \\
\hline Cowichan & 17.92 & 0.48 & 30.27 & 0.03 & 21.87 & 2.82 & 23.35 \\
\hline Haida & 7.02 & 0.12 & 11.26 & 1.04 & 14.55 & 1.09 & 10.94 \\
\hline Meeker & 14.1 & 0.02 & 34.41 & 0.59 & 34.07 & 0.1 & 27.53 \\
\hline Nootka & 8.54 & 0.07 & 16.67 & 0.04 & 18.01 & 0.41 & 14.41 \\
\hline Sumner & 8.06 & 0.04 & 13.16 & 0.72 & 26.93 & 1.88 & 16.05 \\
\hline Tulameen & 21.41 & 0.07 & 40.61 & 2.39 & 24.44 & 1.34 & 28.82 \\
\hline Washington & 10.81 & 0.09 & 22.83 & 0.08 & 25.58 & 0.9 & 19.74 \\
\hline Willamette & 14.87 & 0.45 & 27.55 & 1.98 & 25.04 & 0.2 & 22.49 \\
\hline Overall annual mean & 13.73 & & 23.44 & & 25.56 & & \\
\hline Genotype & $<0.001$ & & & & & & \\
\hline Year & $<0.001$ & & & & & & \\
\hline Genotype $\times$ Year & $<0.001$ & & & & & & \\
\hline
\end{tabular}


Table 2

Ascorbic acid contents (mg per $100 \mathrm{~g}$ of fresh fruit) among three sites: PARC, HK, and AK. Overall mean and SEM of two technical replicates are shown. $P$-values for 2 -way ANOVAs for plant, site, and plant $\times$ site interaction are presented below each genotype

\begin{tabular}{|c|c|c|c|c|c|c|}
\hline & \multicolumn{6}{|c|}{ Sites } \\
\hline & \multicolumn{2}{|c|}{ PARC } & \multicolumn{2}{|c|}{ HK } & \multicolumn{2}{|c|}{$\mathrm{AK}$} \\
\hline & Mean & SEM & Mean & SEM & Mean & SEM \\
\hline \multicolumn{7}{|l|}{ Genotype 36} \\
\hline \multicolumn{7}{|l|}{ Plant } \\
\hline 1 & 25.12 & 0.76 & 33.28 & 0.00 & 30.60 & 0.71 \\
\hline 2 & 30.15 & 3.46 & 29.99 & 0.19 & 43.96 & 1.87 \\
\hline 3 & 25.99 & 2.75 & 42.67 & 3.72 & 26.53 & 3.19 \\
\hline Overall site mean & 27.09 & & 35.31 & & 33.70 & \\
\hline Plant & 0.071 & & & & & \\
\hline Site & 0.004 & & & & & \\
\hline Plant $\times$ Site & 0.002 & & & & & \\
\hline \multicolumn{7}{|l|}{ cv. C.Delight } \\
\hline \multicolumn{7}{|l|}{ Plant } \\
\hline 1 & 17.88 & 2.01 & 18.55 & 0.91 & 20.94 & 1.05 \\
\hline 2 & 23.14 & 0.24 & 24.22 & 1.06 & 19.49 & 0.7 \\
\hline 3 & 23.86 & 1.14 & 18.69 & 0.51 & 21.57 & 2.5 \\
\hline Overall site mean & 21.63 & & 20.49 & & 20.67 & \\
\hline Plant & 0.042 & & & & & \\
\hline Site & 0.541 & & & & & \\
\hline Plant $\times$ Site & 0.035 & & & & & \\
\hline \multicolumn{7}{|l|}{ cv. Malahat } \\
\hline \multicolumn{7}{|l|}{ Plant } \\
\hline 1 & 19.30 & 1.06 & 18.85 & 1.01 & 36.18 & 1.44 \\
\hline 2 & 39.13 & 2.12 & 28.39 & 0.40 & 38.89 & 2.92 \\
\hline 3 & 34.03 & 0.16 & 21.92 & 0.61 & 37.79 & 0.71 \\
\hline Overall site mean & 30.82 & & 23.05 & & 37.62 & \\
\hline Plant & $<0.001$ & & & & & \\
\hline Site & $<0.001$ & & & & & \\
\hline Plant $\times$ Site & 0.002 & & & & & \\
\hline
\end{tabular}

Table 3

Anthocyanin peak identities corresponding to Fig. 2A

\begin{tabular}{lccc}
\hline Peak no. & Ion mass & Time & Anthocyanin \\
\hline 1 & 611,287 & 2.6 & Cy-3-sophoroside \\
2 & 449,287 & 3.1 & Cy-3-glucoside \\
3 & $757,611,287$ & 3.2 & Cy-3-(2 $2^{\mathrm{G}}$-glucosylrutinoside \\
4 & 595,271 & 3.3 & Pg-3-sophoroside \\
5 & $595,449,287$ & 3.6 & Cy-3-rutinoside \\
6 & 433,271 & 3.7 & Pg-3-glucoside \\
7 & 741,271 & 3.8 & Pg-3-(2 $2^{\mathrm{G}}$-glucosylrutinoside \\
8 & 579,271 & 4.2 & $\mathrm{Pg}$-3-rutinoside \\
9 & 491,287 & 5.2 & $\mathrm{Cy}-3$ - $O$-(6-acetyl)-glucoside \\
\hline
\end{tabular}




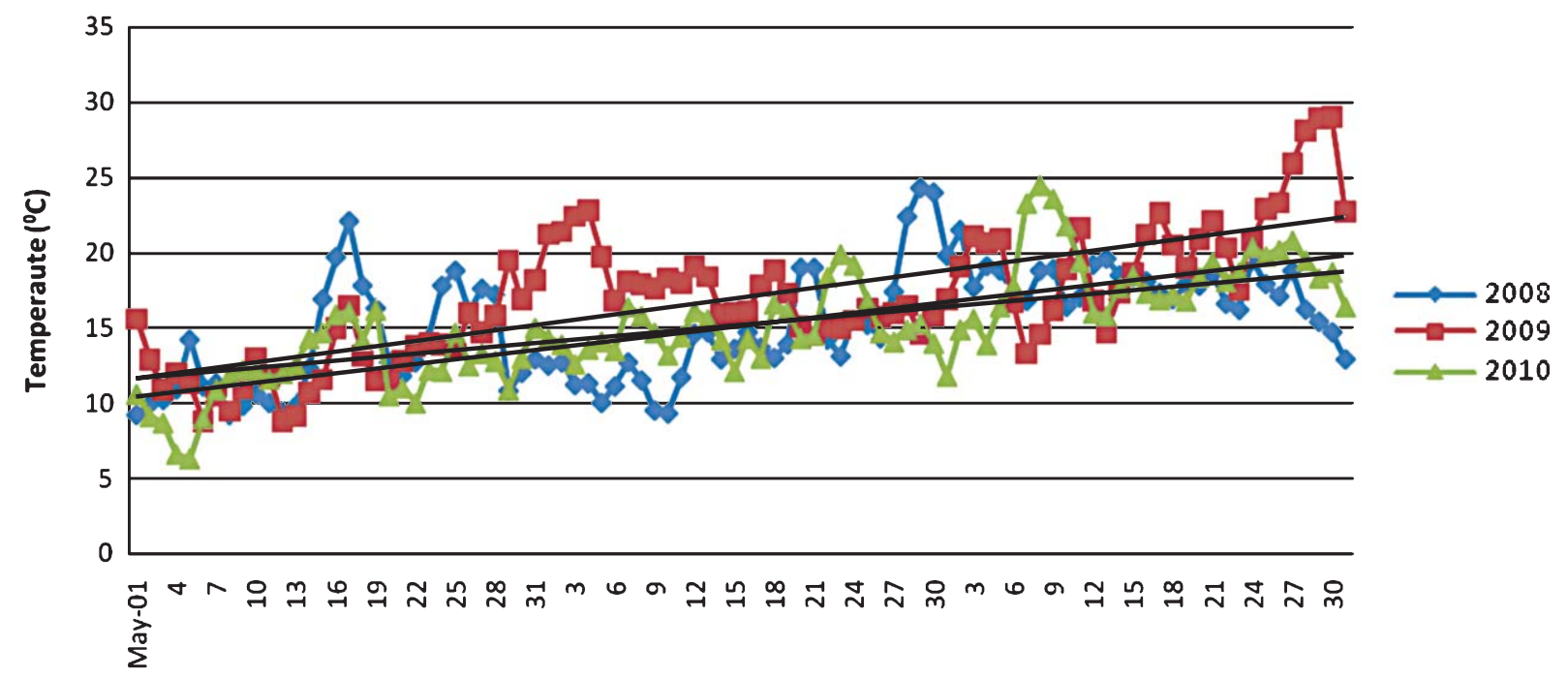

Fig. 1. Average temperature $\left({ }^{\circ} \mathrm{C}\right)$ data along three months (May, June, July) for three years $(2008,2009,2010)$ for the Abbotsford, BC, area as recorded by the government agency (Weather Office, http://www.weatheroffice.gc.ca [15]). Trendlines and equations for each line are shown.
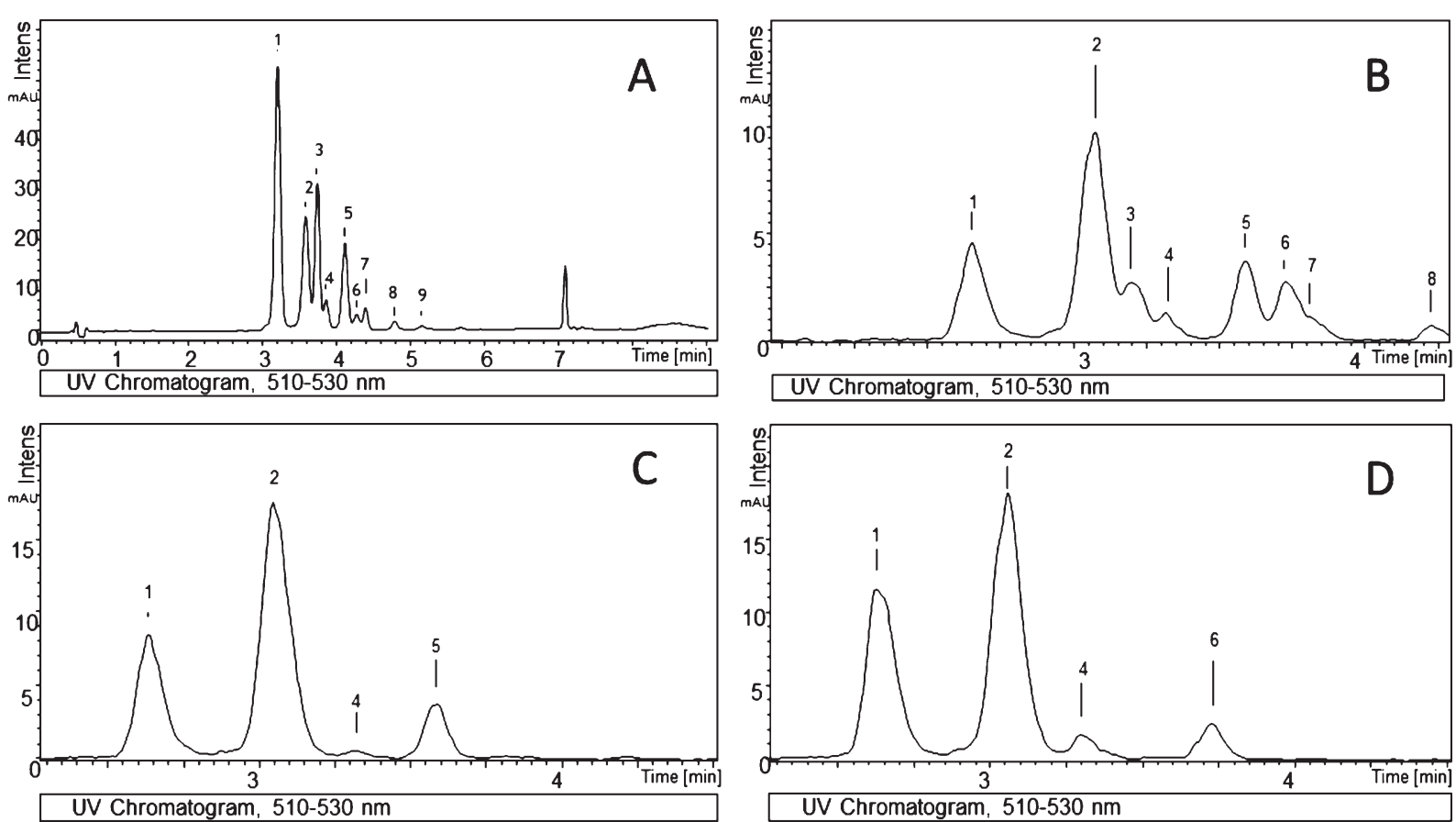

Fig. 2. HPLC chromatograms at $520 \mathrm{~nm}$ of raspberry extracts. For peak annotations, refer to Table 3. A: Pooled raspberry extract for method development and peak identification. B: cv. Cascade Delight. C: genotype 36. D: cv. Malahat.

Commercially available standards were purchased from Extrasynthese (Genay, France); these were cyanidin-3-Oglucoside, cyanidin-3- $O$-sophoroside, pelargonidin-3-O-glucoside, and delphinidin-3- $O$-glucoside. Other peaks, for which no commercial standard was available, were inferred from matching to the MS spectra from Mullen et al. [17] and Beekwilder et al. [13]. 


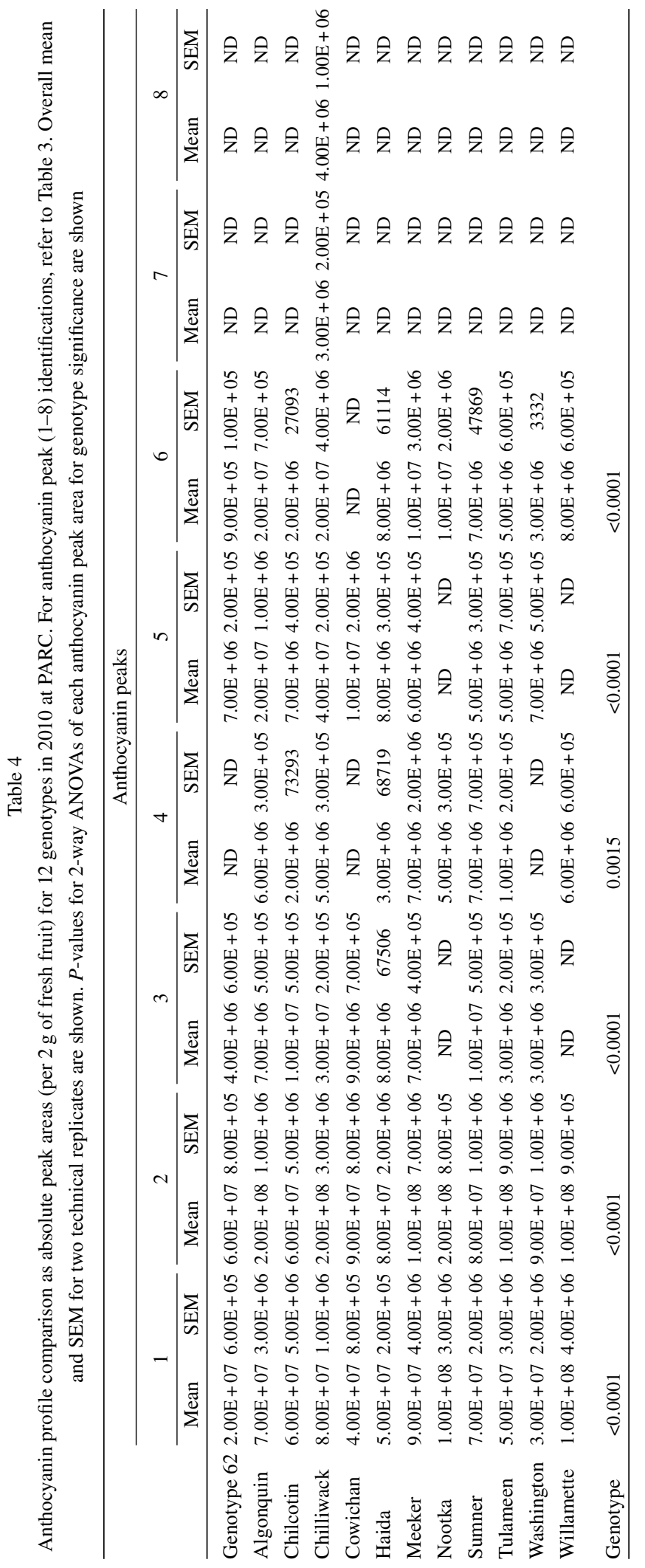


Table 5

Anthocyanin profile comparison (as absolute peak areas) for cv. Cascade Delight among three sites (PARC, HK, AK) for each of three biological replicates (per $2 \mathrm{~g}$ of fresh fruit). For anthocyanin peak (1-8) identifications, refer to Table 3. Overall mean and SEM for two technical replicates are shown. $P$-values for 2 -way ANOVAs of each anthocyanin peak area for plant, site, and plant $\times$ site interaction are presented below

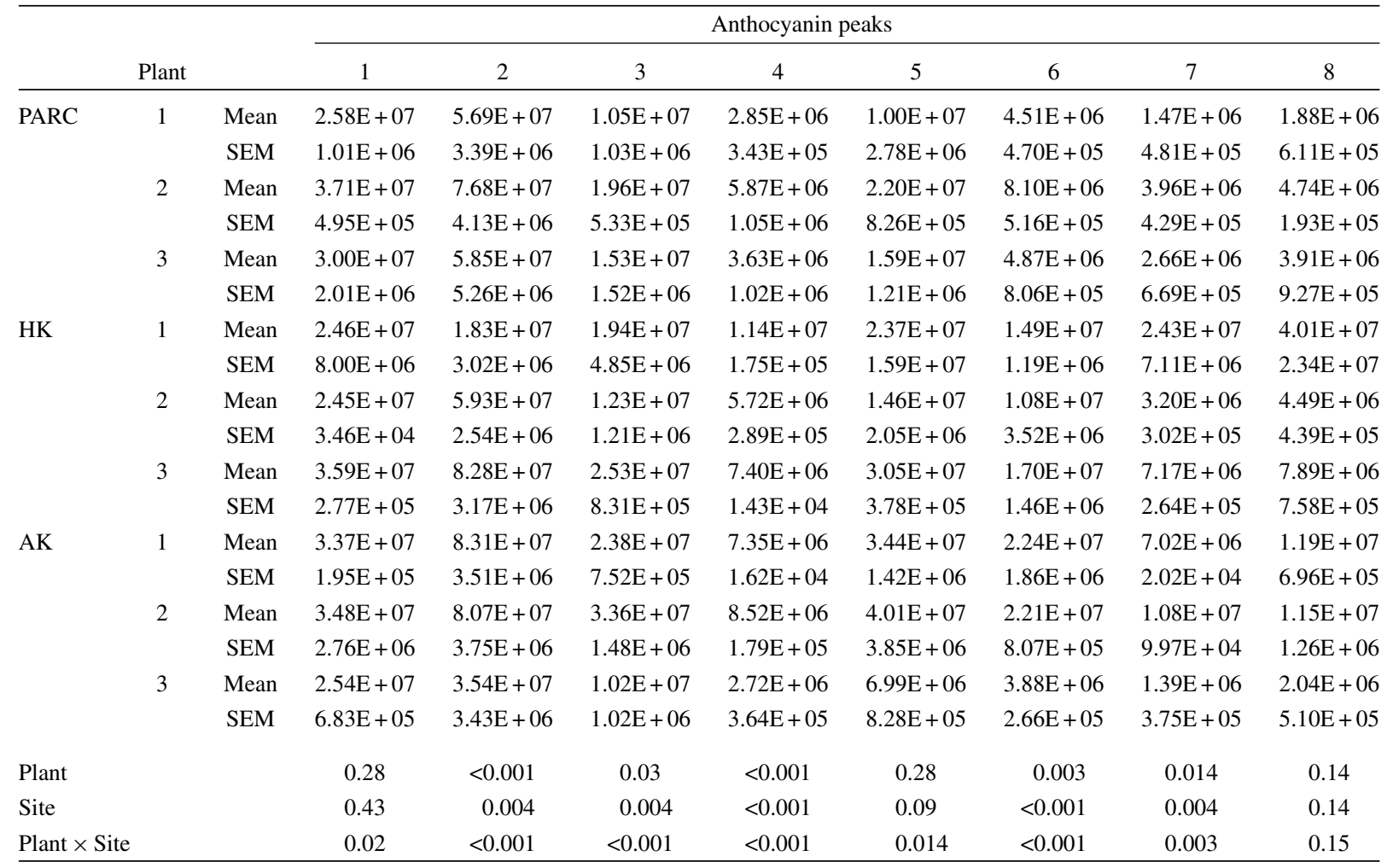

\subsection{Statistical analysis}

Overall means and standard errors of the means (SEMs) presented in the tables were calculated in MS Excel software using means of two replicates each analyzed in triplicate. Analyses of variance (ANOVAs) were done using SAS Version 9.1.3 (SAS Institute Inc., Cary, NC, USA). Statistical significance of differences between parameters was evaluated using two-way ANOVA, where significance of interaction between plant and site (plant $\times$ site) or genotype and year (genotype $\times$ year) was determined.

\section{Results and discussion}

\subsection{Ascorbic acid}

Ascorbic acid content was determined for fruit extracts from each of 12 genotypes (Table 1). Ascorbic acid contents ranged from a low of 7 to $14 \mathrm{mg}$ per $100 \mathrm{~g}$ of $\mathrm{cv}$. Haida fruit to a high in cv. Tulameen which contained up to $40.6 \mathrm{mg}$ per $100 \mathrm{~g}$. Significant differences were obtained in ascorbic acid content for the 12 genotypes sampled from the same site in each of three successive years (Table 1). We detected a general trend that plants exhibiting high concentrations of ascorbic acid also maintained this relative ranking among genotypes irrespective of sampling year, with the exception of genotype 62 for which a decrease in ascorbic acid content occurred in 2009. The differences in ascorbic acid content among the harvest years within genotypes suggest that climate plays an important role in determining the total ascorbic acid content in raspberries at harvest (as can be seen by higher ascorbic acid amounts 
Table 6

Anthocyanin profile comparison (as absolute peak areas) for cv. Malahat among three sites (PARC, HK, AK) for three biological replicates (per $2 \mathrm{~g}$ of fresh fruit). For anthocyanin peak (1, 2, 4, and 6) identification, refer to Table 3. Overall mean and SEM for two technical replicates are shown. $P$-values for 2-way ANOVAs of each anthocyanin peak area for plant, site, and plant $\times$ site interaction are presented below

\begin{tabular}{|c|c|c|c|c|c|c|}
\hline & \multirow[b]{2}{*}{ Plant } & & \multicolumn{4}{|c|}{ Anthocyanin peaks } \\
\hline & & & 1 & 2 & 4 & 6 \\
\hline \multirow[t]{6}{*}{ PARC } & 1 & Mean & $6.43 E+07$ & $9.20 \mathrm{E}+07$ & $4.72 E+06$ & $1.03 \mathrm{E}+07$ \\
\hline & & SEM & $1.51 \mathrm{E}+05$ & $3.76 \mathrm{E}+06$ & $4.95 E+05$ & $1.85 E+06$ \\
\hline & 2 & Mean & $8.08 \mathrm{E}+07$ & $1.28 \mathrm{E}+08$ & $9.90 \mathrm{E}+06$ & $1.46 \mathrm{E}+07$ \\
\hline & & SEM & $8.18 \mathrm{E}+05$ & $5.32 \mathrm{E}+06$ & $8.64 \mathrm{E}+05$ & $7.68 \mathrm{E}+05$ \\
\hline & 3 & Mean & $5.99 \mathrm{E}+07$ & $9.57 \mathrm{E}+07$ & $5.18 \mathrm{E}+06$ & $8.09 E+06$ \\
\hline & & SEM & $5.67 \mathrm{E}+06$ & $6.39 \mathrm{E}+06$ & $1.50 \mathrm{E}+06$ & $1.08 \mathrm{E}+05$ \\
\hline \multirow[t]{6}{*}{$\mathrm{HK}$} & 1 & Mean & $7.09 \mathrm{E}+07$ & $1.13 E+08$ & $6.20 \mathrm{E}+06$ & $1.22 \mathrm{E}+07$ \\
\hline & & SEM & $3.42 \mathrm{E}+05$ & $4.27 \mathrm{E}+04$ & $1.27 \mathrm{E}+05$ & $8.72 E+04$ \\
\hline & 2 & Mean & $9.07 \mathrm{E}+07$ & $1.34 \mathrm{E}+08$ & $9.41 E+06$ & $1.20 \mathrm{E}+07$ \\
\hline & & SEM & $2.19 \mathrm{E}+06$ & $8.89 \mathrm{E}+05$ & $5.60 \mathrm{E}+04$ & $6.40 \mathrm{E}+05$ \\
\hline & 3 & Mean & $5.59 \mathrm{E}+07$ & $1.02 \mathrm{E}+08$ & $3.84 \mathrm{E}+06$ & $9.73 E+06$ \\
\hline & & SEM & $1.94 \mathrm{E}+06$ & $6.10 \mathrm{E}+06$ & $1.54 \mathrm{E}+05$ & $1.56 \mathrm{E}+06$ \\
\hline \multirow[t]{6}{*}{$\mathrm{AK}$} & 1 & Mean & $5.75 \mathrm{E}+07$ & $1.42 \mathrm{E}+08$ & $5.86 \mathrm{E}+06$ & $2.45 \mathrm{E}+07$ \\
\hline & & SEM & $2.37 \mathrm{E}+05$ & $3.03 E+06$ & $1.17 \mathrm{E}+05$ & $2.93 \mathrm{E}+05$ \\
\hline & 2 & Mean & $5.02 \mathrm{E}+07$ & $1.03 E+08$ & $3.35 \mathrm{E}+06$ & $1.15 E+07$ \\
\hline & & SEM & $3.62 \mathrm{E}+06$ & $1.10 \mathrm{E}+07$ & $1.42 \mathrm{E}+05$ & $9.73 E+05$ \\
\hline & 3 & Mean & $5.51 \mathrm{E}+07$ & $9.83 E+07$ & $6.89 \mathrm{E}+06$ & $1.02 \mathrm{E}+07$ \\
\hline & & SEM & $1.00 \mathrm{E}+06$ & $1.20 \mathrm{E}+06$ & $2.16 \mathrm{E}+06$ & $3.02 \mathrm{E}+05$ \\
\hline Plant & & & $<0.001$ & 0.0013 & $<0.001$ & $<0.001$ \\
\hline Site & & & $<0.001$ & 0.062 & $<0.001$ & $<0.001$ \\
\hline Plant $\times$ Site & & & $<0.001$ & $<0.001$ & $<0.001$ & $<0.001$ \\
\hline
\end{tabular}

in 2009 where mean temperatures were generally higher towards July) but the reasonably consistent relative amounts among genotypes argue against a strong environmental component to heritability of this trait. When we examined site and plant variation in ascorbic acid (Table 2), we detected significant differences $(p<0.05)$ in plant to plant variation for cvs. Cascade Delight and Malahat and significant site differences for genotype 36 and cv. Malahat. There was a significant plant $\times$ site interaction, which suggests that growing conditions on each site affect the total ascorbic acid content on plants cultivated in different areas in the Fraser Valley area.

\subsection{Anthocyanin identification and variation}

It was previously determined that anthocyanins also contribute to the total antioxidant capacity of red raspberries [13]. The major anthocyanin determined for raspberry was cyanidin-derived glucosides, with a relatively minor presence of pelargonidin-derived glucosides (Table 3), which is consistent with thefindings of Mullen et al. [17], Scalzoet al. [18], and Wu et al. [19].

Once the anthocyanin profile was established, it was then used as a reference for further analyses requiring peak identification (Fig. 2A and Table 3). Profiles for Cascade Delight (Fig. 2B), genotype 36 (Fig. 2C), and Malahat (Fig. 2D) were determined and compared among three sites for the 2010 samples, as well as for 12 cultivars from PARC. Amounts of individual anthocyanins for each sample are represented in Tables 4, 5, 6, and 7 as absolute peak areas. 
Table 7

Anthocyanin profile comparison (as absolute peak areas) for genotype 36 among three sites (PARC, HK, AK) for three biological replicates (per $2 \mathrm{~g}$ of fresh fruit). For anthocyanin peak (1, 2, 4, and 5) identification, refer to Table 3. Overall mean and SEM for two technical replicates are shown. $P$-values for 2-way ANOVAs of each anthocyanin peak area for plant, site, and plant $\times$ site interaction are presented below

\begin{tabular}{|c|c|c|c|c|c|c|}
\hline & \multirow[b]{2}{*}{ Plant } & & \multicolumn{4}{|c|}{ Anthocyanin peaks } \\
\hline & & & 1 & 2 & 4 & 6 \\
\hline \multirow[t]{6}{*}{ PARC } & 1 & Mean & $6.43 E+07$ & $9.20 \mathrm{E}+07$ & $4.72 \mathrm{E}+06$ & $1.03 \mathrm{E}+07$ \\
\hline & & SEM & $1.51 \mathrm{E}+05$ & $3.76 \mathrm{E}+06$ & $4.95 E+05$ & $1.85 \mathrm{E}+06$ \\
\hline & 2 & Mean & $8.08 \mathrm{E}+07$ & $1.28 \mathrm{E}+08$ & $9.90 \mathrm{E}+06$ & $1.46 \mathrm{E}+07$ \\
\hline & & SEM & $8.18 \mathrm{E}+05$ & $5.32 \mathrm{E}+06$ & $8.64 \mathrm{E}+05$ & $7.68 \mathrm{E}+05$ \\
\hline & 3 & Mean & $5.99 \mathrm{E}+07$ & $9.57 \mathrm{E}+07$ & $5.18 \mathrm{E}+06$ & $8.09 \mathrm{E}+06$ \\
\hline & & SEM & $5.67 \mathrm{E}+06$ & $6.39 \mathrm{E}+06$ & $1.50 \mathrm{E}+06$ & $1.08 \mathrm{E}+05$ \\
\hline \multirow[t]{6}{*}{ HK } & 1 & Mean & $7.09 \mathrm{E}+07$ & $1.13 \mathrm{E}+08$ & $6.20 \mathrm{E}+06$ & $1.22 \mathrm{E}+07$ \\
\hline & & SEM & $3.42 \mathrm{E}+05$ & $4.27 \mathrm{E}+04$ & $1.27 \mathrm{E}+05$ & $8.72 \mathrm{E}+04$ \\
\hline & 2 & Mean & $9.07 \mathrm{E}+07$ & $1.34 \mathrm{E}+08$ & $9.41 \mathrm{E}+06$ & $1.20 \mathrm{E}+07$ \\
\hline & & SEM & $2.19 \mathrm{E}+06$ & $8.89 \mathrm{E}+05$ & $5.60 \mathrm{E}+04$ & $6.40 \mathrm{E}+05$ \\
\hline & 3 & Mean & $5.59 \mathrm{E}+07$ & $1.02 \mathrm{E}+08$ & $3.84 \mathrm{E}+06$ & $9.73 E+06$ \\
\hline & & SEM & $1.94 \mathrm{E}+06$ & $6.10 \mathrm{E}+06$ & $1.54 \mathrm{E}+05$ & $1.56 \mathrm{E}+06$ \\
\hline \multirow[t]{6}{*}{$\mathrm{AK}$} & 1 & Mean & $5.75 \mathrm{E}+07$ & $1.42 \mathrm{E}+08$ & $5.86 \mathrm{E}+06$ & $2.45 \mathrm{E}+07$ \\
\hline & & SEM & $2.37 \mathrm{E}+05$ & $3.03 E+06$ & $1.17 \mathrm{E}+05$ & $2.93 \mathrm{E}+05$ \\
\hline & 2 & Mean & $5.02 \mathrm{E}+07$ & $1.03 \mathrm{E}+08$ & $3.35 \mathrm{E}+06$ & $1.15 \mathrm{E}+07$ \\
\hline & & SEM & $3.62 \mathrm{E}+06$ & $1.10 \mathrm{E}+07$ & $1.42 \mathrm{E}+05$ & $9.73 E+05$ \\
\hline & 3 & Mean & $5.51 \mathrm{E}+07$ & $9.83 \mathrm{E}+07$ & $6.89 \mathrm{E}+06$ & $1.02 \mathrm{E}+07$ \\
\hline & & SEM & $1.00 \mathrm{E}+06$ & $1.20 \mathrm{E}+06$ & $2.16 \mathrm{E}+06$ & $3.02 \mathrm{E}+05$ \\
\hline Plant & & & 0.03 & 0.019 & 0.80 & 0.33 \\
\hline Site & & & $<0.001$ & 0.01 & 0.60 & 0.15 \\
\hline Plant $\times$ Site & & & 0.12 & 0.69 & 0.14 & 0.12 \\
\hline
\end{tabular}

Anthocyanin profiles for each of the 12 genotypes in PARC in 2010 were also determined (Table 4). Cv. Chilliwack had the most diverse profile for which eight peaks were found and identified, while the rest of the varieties ranged from four to six different anthocyanins. Peak area comparison also revealed that cv. Chilliwack not only had the most complex profile, but also one of the highest amounts of cyanidin-3- $O$-sophoroside (peak 1 ).

Among the three genotypes tested, cv. Cascade Delight was the one other cultivar that had the most complex profile with eight different anthocyanins (Table 5), whereas only four anthocyanins were resolved for cv. Malahat and genotype 36 (Tables 6 and 7). Figure 2 (B, C, D) shows the different anthocyanin compositions for cvs. Cascade Delight, genotype 36, and Malahat, respectively. Tables 5, 6, and 7 show specifically which anthocyanins significantly differed among plants, sites, and plant $\times$ site. With the exception of genotype 36 , the site $\times$ plant interaction was significant, suggesting that there is an effect of the growing conditions of each site on the amount of a particular anthocyanin present.

\section{Conclusion}

Raspberries are a good natural source of ascorbic acid and anthocyanins, as well as other antioxidant compounds, including tannins such as ellagic acid. Compelling epidemiological evidence supports the consumption of pigmented soft fruits such as raspberries as being part of a healthy diet. Increasing consumer attention to antioxidant phenotypes in a healthy diet provides an economically sound basis for incorporating selections for these traits to existing raspberry breeding programs. The data from our study support the feasibility of this strategy given the significant differences 
among genotypes in the antioxidant phytochemicals, ascorbic acid and several anthocyanins. It is unclear from in vitro and animal model studies as to which individual anthocyanins may be most important for antioxidant traits. Future studies, including breeding of raspberry genotypes with varied anthocyanin composition phenotypes and testing of progeny using similar experimental tools as above, will provide an applied means of assessing heritable effects of different anthocyanin compositions on total antioxidant capacity.

\section{Acknowledgments}

This work was supported by the UBC Faculty of Land and Food Systems Vitamin Research Fund. We thank Mr. Harvey Krause, Mr. Alf Krause, and the Pacific Agri-food Research Centre for access to raspberry materials. We thank staff and students in the labs of Dr. Lund and Dr. K. Ritland for assistance with plant material collections. Special thanks go to Ms. Lina Madilao for training and expert assistance with LC-MS analyses and Dr. Tony Kozak for guidance on the use of SAS software and interpretation of the statistical data.

\section{References}

[1] Zhang Y, Vareed SK, Nair MG. Human tumor cell growth inhibition by nontoxic anthocyanidins, the pigments in fruits and vegetables. Life Sciences. 2005; 76(13): 1465-72.

[2] Wiseman W, Egan JM, Slemmer JE, Shaughnessy KS, Ballem K, Gottschall-Pass KT, Sweeney MI. Feeding blueberry diets inhibits angiotensin II-converting enzyme (ACE) activity in spontaneously hypertensive stroke-prone rats. Can J PhysiolPharmacol. 2011; 89(1): 67-71.

[3] Edirisinghe I, Banaszewski K, Cappozzo J, McCarthyD, Burton-Freeman BM. Effect of black currant anthocyanins on the activation of endothelial nitric oxide synthase (eNOS) in vitro in human endothelial cells. J Agric Food Chem. 2011; 59(16): 8616-24.

[4] Mense SM, Singh B, Remotti F, Liu X, Bhat HK. Vitamin C and alpha-naphthoflavone prevent estrogen-induced mammary tumors and decrease oxidative stress in female ACI rats. Carcinogenesis. 2007; 30(7): 1202-8.

[5] Sahni S, Hannan MT, Gagnon D, Blumberg J, Cupples LE, Kiel DP, Tucker KL. Protective effect of total and supplemental vitamin C intake on the risk of hip fracture-a 17-year follow-up from the Framingham osteoporosis study. Osteoporos Int. 2009; $20(11)$ : 1853-61.

[6] Levine M, Rumsey SC, Wang Y, Park JB, Daruwala R. Vitamin C. In: Stipanuk MH, editor. Biochemical and physiological aspects of human nutrition. Philadelphia: W B Saunders; 2002. p. 541-67.

[7] Prockop DJ, Kivirikko KI. Collagens: Molecular biology, diseases, and potentials for therapy. Annu Rev Biochem. 1995 ; 64: $403-34$.

[8] Rebouche CJ. Ascorbic acid and carnitine biosynthesis. Am J Clin Nutr. 1991; 54: 1147-52.

[9] Levine M, Dhariwal KR, Washko P, Welch R, Wang YH, Cantilena CC, Yu R. Ascorbic acid and reaction kinetics in situ: A new approach to vitamin requirements. J Nutr Sci Vitaminol. 1992; Spec No: 169-72. Available from: http://www.ncbi.nlm.nih.gov/pubmed/1297733.

[10] Englard S, Seifter S. The biochemical functions of ascorbic acid. Annu Rev Nutr. 1986; 6: 365-406.

[11] Poiroux-Gonord F, Bidel PR, Fanciullino AL, Gautier H, Lauri-Lopez F, Urban L. Health benefits of vitamins and secondary metabolites of fruits and vegetable and prospects to increase their concentration by agronomic approaches. J Agric Food Chem. 2010; 58(23): 12065-82.

[12] Scalzo J, Battino M, Costantinia E, Mezzetti B. Breeding and biotechnology for improving berry nutritional quality. Biofactors. 2005; 23(4): 213-20.

[13] Beekwilder J, Jonker H, Meesters P, Hall RD, Van der Meer IM, Ric de Vos CH. Antioxidants in raspberry: On-line analysis links antioxidant activity to a diversity of individual metabolites. J Agric Food Chem. 2005; 53(9): 3313-20.

[14] Tosun M, Ercisli S, Karlidag H, Sengul M. Characterization of red raspberry (Rubus idaeus L.) genotypes for their physicochemical properties. J Food Sci. 2009; 74(7): 575-9.

[15] Weatheroffice [homepage on the Internet]. Canada: Environment Canada, Weatheroffice; current [updated 2012 Feb 02; cited 2012April 30]. Available from: http://www.weatheroffice.gc.ca.

[16] Frenich AG, Hernandez Torres ME, Vega AB, Martinez Vidal JL, Bolanos PP. Determination of ascorbic acid and carotenoids in food commodities by liquid chromatography with mass spectrometry detection. J Agric Food Chem. 2005; 53(19): 7371-6.

[17] Mullen W, Lean MEJ, Crozier A. Rapid characterization of anthocyanins in red raspberry fruit by high-performance liquid chromatography coupled to single quadrupole mass spectrometry. J Chromatogr. 2002; 966(1-2): 63-70.

[18] Scalzo J, Currie A, Stephens J, McGhie T, Alspach P. The anthocyanin composition of different Vaccinium, Ribes, and Rubus genotypes. Biofactors. 2008; 34(1): 13-21.

[19] Wu X, Beecher GR, Holden JM, Haytowitz DB, Gebhardt SE, Prior RL. Concentrations of anthocyanins in common foods in the United States and estimation of normal consumption. J Agric Food Chem. 2006; 54(11): 4069-75. 